\title{
Very Near-Field Plume Investigation of the D55
}

\author{
Matthew T. Domonkos*, Colleen M. Marrese*, James M. Haas", and Alec D. Gallimore ${ }^{\ddagger}$ \\ Plasmadynamics and Electric Propulsion Lab (PEPL) \\ The University of Michigan \\ Ann Arbor, MI 48109
}

\begin{abstract}
The plasma properties of the very near-field $(10$ to $50 \mathrm{~mm}$ ) plume of the D55 anode layer thruster (TAL) were measured as part of an effort lead by NumerEx of Albuquerque, NM to model the processes within TALs. The D55 is the $1.35 \mathrm{~kW}$ TAL counterpart to the SPT-100 and was made by TsNLMASH of Kaliningrad, Russia. The thruster was tested in the $6 \mathrm{~m}$ diameter by $9 \mathrm{~m}$ long vacuum chamber at the Plasmadynamics and Electric Propulsion Laboratory (PEPL), and the diagnostic probes were positioned using a three axis translation table system. A Faraday probe, water-cooled Hall probes, emissive probes, and Langmuir probes were used to examine the near-field plasma properties. Water-cooled Hall probes were employed to explore the effect of the closed drift current on the radial magnetic field. The change in the magnetic field due to the Hall current was found to be less than five percent over the region examined. Ion current density profiles showed that the annular beam focuses within $40 \mathrm{~mm}$ of the thruster exit plane. Similarly, the electron temperature and number density radial profiles showed peaks near the discharge chamber at $10 \mathrm{~mm}$ axially, and the peaks moved toward the axis within $40 \mathrm{~mm}$. The peak electron temperature decreased with axial distance, while the number density remained approximately constant over the very near-field region.
\end{abstract}

\section{Nomenclature}
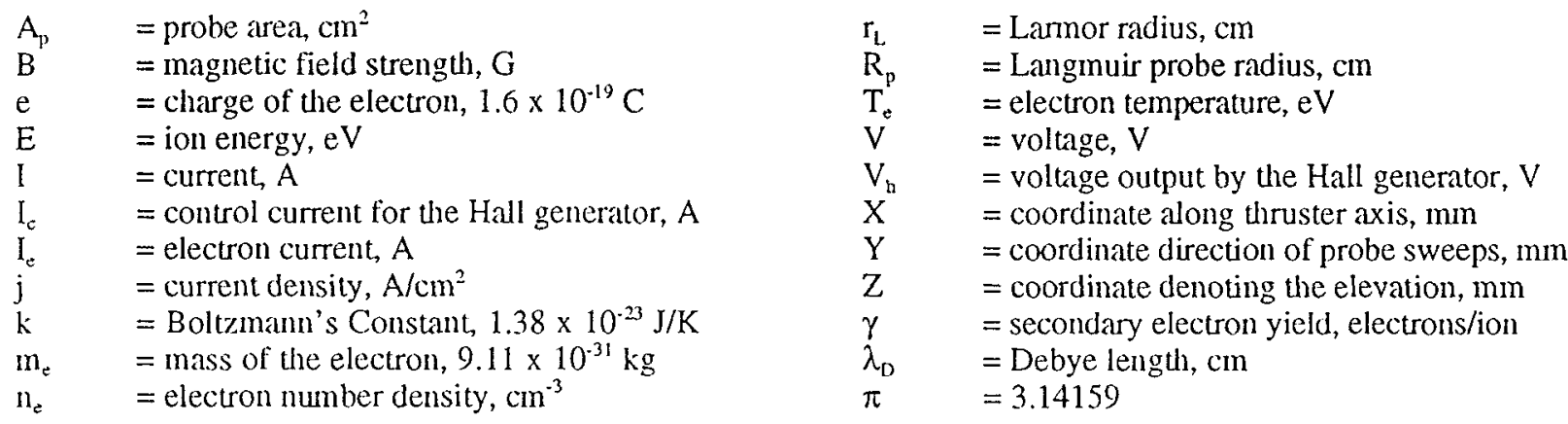

Introduction

The D55 anode layer thruster (TAL) built by the Central Scientific Research Institute of Machine Building (TsNIIMASH) of Kaliningrad, Russia offers perfornance and projected lifetime similar to that of the SPT-100.1.2 While this design is the result of years of empirically and theoretically derived improvements, current technology computer simulations have recently been employed to examine the physics of Hall thrusters without the need for analytic solutions of the governing equations. ${ }^{3.4}$ By analyzing the physics with the greater detail afforded by numerical examination, the perfornance envelope of Hall thrusters can be explored and extended more effectively. NumerEx of Albuquerque, NM is currently under contract with the Jet Propulsion Laboratory (JPL) to develop a MHD model of the operation of the D55. The Plasmadynamics and Electric Propulsion Laboratory (PEPL) was subcontracted by NumerEx to provide experimental data for code validation. This paper presents the results of the very near-field investigation along with first order calculation of some properties of the discharge.

The D55 TAL has a well documented experimental heritage with A.V. Zharinov first proposing the design in the early $1960 \mathrm{~s}^{5}$ Since the advent of Russian-American joint technological ventures in the early $1990 \mathrm{~s}$, the TAL has been under intensive experimental investigation in the United States. ${ }^{5.7 .8}$ The D55 is an alternative $1.35 \mathrm{~kW}$

\footnotetext{
- Graduate Student Research Assistant, Aerospace Engineering, Member AlAA.

${ }^{\ddagger}$ Assistant Professor, Aerospace Engineering and Applied Physics, Senior Member AIAA.

Copyright (c) 1997 by Matthew T. Dononkos, Published by the American Institute of Aeronautics and Astronautics with permission.
} 
thruster to the SPT-100 and T-100, with the benefits of increased thrust density and potentially greater lifetime. ${ }^{6}$ The work to date has focused on performance evaluation, examination of lifetime limiters, and far field plume studies to assess spacecraft integration issues. ${ }^{5,7.8}$ Ganer, et al. ${ }^{5}$ conducted a 636 hour test of the D55 which focused on performance mapping. Spacecraft integration issues were addressed in the work by Manzella which focused primarily on far-field plasma properties. In an effort to explain the erosion observed during the 636 hour test, Marrese, et al. ${ }^{8}$ measured the magnetic field generated by the electromagnets alone both within and upstream of the discharge region.

While the vacuum magnetic field in Hall thrusters is expected to dominate the overall topography, the $\vec{E} \times \vec{B}$ closed drift of electrons may play a significant role in determining the field during thruster operation. Measurement of the magnetic field during thruster operation is one of the primary goals of the current investigation. Comparison of the field strengths from the magnets alone and during thruster operation enables estimation of the magnitude of the closed electron drift and is of use for modeling efforts like the one at NumerEx. To measure the magnetic field in the intense ion beam present in the near field of the thruster, water cooled Hall probes were constructed which protect the delicate semiconducting Hall generator from the particle and radiative fluxes from the thruster. In addition to the magnetic field measurements, this investigation seeks to generate a map of plasma properties from 10 to $50 \mathrm{~mm}$ from the exit plane with greater radial resolution than previous work. ${ }^{9}$ Experiments performed by TSNIIMASH have shown electron temperatures above $20 \mathrm{eV}$ and plasma potentials of tens of volts within $1.5 \mathrm{~cm}$ of the thruster. Previous work at PEPL has illustrated some of the difficulties with examining the very near-field plasma generated by a Hall thruster. ${ }^{10} \mathrm{Kim}$, Foster, and Gallimore ${ }^{10}$ found electron temperatures and number densities of up to $8 \mathrm{eV}$ and $3 \times 10^{12} \mathrm{~cm}^{-3}$. These examinations provide a basis upon which to design electrostatic probes for this work.

This paper begins by describing the equipment used in this investigation. The experimental procedure is then described, followed by a presentation of the key results. The measurements of the magnetic field, ion current density, and electron temperature and number density are discussed, and a summary of the important results is presented.

\section{Experimental Apparatus}

All of the experiments were conducted in the PEPL $6 \mathrm{~m}$ diameter by $9 \mathrm{~m}$ long vacuum chamber, shown schematically in Figure 1. The facility is evacuated to high vacuum using six $0.81 \mathrm{~m}$ diameter oil diffusion pumps. For these tests, the pumps provided a pumping speed of approximately $30000 \mathrm{~L} / \mathrm{s}$ on Xe, and the facility pressure was maintained at $8.3 \times 10^{-3} \mathrm{~Pa}$ during testing. A mass flow system controlled with micrometer valves at the vacuum feedthrough supplied 99.999 percent pure Xe to the thruster.

\section{Thruster}

The D55 TAL shown schematically in Figure 2 was provided to PEPL by the Jet Propulsion Laboratory. The "55" indicates the mean diameter of the anode in millimeters. Figure 2 also defines the coordinate system used to refer to the data. The anode extends in an annulus to the exit plane of the thruster, which utilizes three outer electromagnets in contrast to the four in the SPT-100. The electromagnets were operated independently of the discharge at currents determined by TsNIIMASH. $\mathrm{A} \mathrm{LaB}_{6}$ hollow cathode designed by the Moscow Aviation Institute was used in these tests. The centerline of the cathode was oriented at $45^{\circ}$ to the centerline of the thruster. The point described by the intersection of the cathode centerline and exit plane was $3 \mathrm{~cm}$ from the outer edge of the anode in positive $X$ and $Z$ directions. The cathode centerline fell along the $Y=+7 \mathrm{~mm}$ plane of the thruster. During operation, the cathode consumed $0.78 \mathrm{mg} / \mathrm{s}$ of Xe. The thruster operated at a flowrate of $4.76 \mathrm{mg} / \mathrm{s}$ of Xe, a current of $4.5 \mathrm{~A}$, and a discharge voltage of $300 \mathrm{~V}$. Table 1 summarizes the nominal operating conditions during these tests. The discharge was regulated using a $\mathrm{RC}$ filter with values of $25 \Omega$ and $105 \mu \mathrm{F}$, respectively. Discharge was initiated at about $50 \mathrm{~V}$ and $3.0 \mathrm{~A}$ using the cathode ignitor. After heating for several minutes, the thruster was shut off and immediately restarted at high voltage ( $>200 \mathrm{~V}$ on the discharge) to mitigate power supply problems associated with the transition of the thruster from low voltage $(<100 \mathrm{~V})$ to high voltage operation. The thruster was mounted on a post connected to the same plate as the positioning system, as shown in Figure 3. This configuration prevented misalignment of the diagnostic probes due to warping of the chamber under vacuum.

\section{Positioning System}

A three axis positioning system was used to move probes into the very near-field of the D55. Only the vacuum magnetic field generated by the electromagnets was measured using the configuration shown in Figure 3. Attempts 
were made to use this system to obtain data during thruster operation. However, observation of the discharge current using a Tektronix A6303 current probe and a Tektronix 540 digital oscilloscope indicated that the structure of the vertical translation table interfered with the discharge. Although it may be feasible to place probes at the end of a boom to minimize plasma perturbation, all of the data collected with the thruster on utilized only two axes with the probes in the X-Y plane. Elimination of the vertical translation stage permitted minimization of the probe support structure. All reported positions are accurate to within $2 \mathrm{~mm}$.

Using the positioning system, data were gathered in sweeps along the $Y$-axis for the Hall and Faraday probes. A single sweep contained several hundred samples along a line of constant $X$ and $Z$, and consequently, these data are reported here as continuous curves for clarity in the plots. Vacuum magnetic field data sweeps were gathered at discrete values of $X$ and $Z$, ranging from $5 \mathrm{~mm}$ to $50 \mathrm{~mm}$ and $-60 \mathrm{~mm}$ to $40 \mathrm{~mm}$, respectively. In order to report radial magnetic field data, the $Y$ and $Z$ components measured separately with a transverse Hall probe were used to calculate the radial field at discrete points in a 21 by 100 matrix in a plane of constant $X$. Ion current densities were measured only along lines of constant $X$ and $Z=0$ in the $X-Y$ plane. Both the magnetic field and the ion current density measurements were recorded on a digital oscilloscope to insure that the sampling rate was sufficient to capture the important features of the data. In contrast, measurements made with the Langmuir and emissive probes were taken by positioning the probe at a single point in the plume, gathering the data, then moving the probe out of the plume.

\section{Hall Probes}

Figure 4 shows the water cooled Hall probes used to measure the magnetic fields of both the electromagnets and of the thruster during operation. Magnetic fields deflect the constant current, $I_{c}$, supplied to the Hall generator, which results in the generation of an electric field in the direction mutually perpendicular to the constant current and the magnetic field. The induced voltage, $\mathrm{V}_{\mathrm{H}}$, is proportional to the applied magnetic field. Since the Hall generator is a semiconductor device, the operating temperature must remain below $100^{\circ} \mathrm{C}$. F.W. Bell BH-208 axial and BH-209 transverse Hall generators comprised the sensor elements on two separate probe assemblies. The generators were mounted to non-magnetic stainless steel water cooling tubes using ceramic cement. This configuration provided a thermal conduction path from the Hall probe to the cooling tubes and a radiation shield of ceramic cement for the probe. In addition to these thermal management systems, a Pyrex flux shield insulated the Hall probe elements against heat deposition by plasma bombardment. A VWR Scientific refrigerated recirculator maintained an inlet water temperature of $7^{\circ} \mathrm{C}$. A small Type $\mathrm{K}$ thermocouple was used to monitor the temperature of the Hall probe so that thermal drift of the sensitivity was mitigated. If the temperature drifted beyond $24^{\circ} \mathrm{C}$, the probe was left out of the plume for an extended period to reduce the temperature.

Since the output of the Hall probe was expected to be on the order of hundreds of microvolts, the signal was amplified within $1 \mathrm{~m}$ of the Hall generator by a 1000 gain Analog Devices 524AD precision instrumentation amplifier. The output was recorded on the oscilloscope. A Lambda LPD-422A-PM power supply provided the constant current, $I_{c}$, to drive the probes.

A NIST traceable Walker Scientific Inc. MG-5DAR Gaussmeter was used to calibrate the Hall probes. Figure 5a shows the calibration of the transverse probe with respect to the Gaussmeter, and Figure 5b shows that a strong axial electric field had a negligible effect on the sensitivity of the generator. The non-zero voltage at zero magnetic field was the result of an imperfect Hall generator and constituted an offset. The offset may be adjusted using the potentiometers in Figure $4 \mathrm{~b}$. Figure $5 \mathrm{~b}$ shows a hysteresis loop because the cores of the Helmholtz coils were slightly ferromagnetic, and the applied current would. Consequently, the order in which the data were taken was identical for all calibrations in order to insure accuracy. An electromagnet was positioned inside the vacuum chamber to provide in-situ calibration of the probes. A discussion of the overall accuracy of the magnetic field measurements is presented later.

\section{Electrostatic Probes}

A planar Faraday probe consisting of a $2.4 \mathrm{~mm}$ diameter tungsten rod sheathed in an alumina tube was used to measure the ion current density. The probe was insulated from the plasma except for the end which collected the ion current. A guard ring was omitted since it would be ineffective in eliminating the edge effects of the collector across the insulating alumina tube which extended several tens of Debye lengths radially. The probe was biased $-70 \mathrm{~V}$ with respect to ground, which was deemed sufficient to repel the electron current since further negative increases resulted 
in no additional ion current. Secondary electron emission by Xe bombardment of the tungsten probe was taken into account using Equation 1:

$$
\mathrm{J}_{\mathrm{i}}=\mathrm{J}_{\mathrm{i}, \mathrm{FP}}-\gamma(\langle\mathrm{E}\rangle) \mathrm{J}_{\mathrm{i}, \mathrm{FP}}
$$

where $\gamma$ is the secondary electron yield evaluated at the average ion energy. Since the yield for Xe ions bombarding tungsten is virtually constant over the range of possible ion energies, a value of 0.02 was used in the reported current densities." Current was determined by measuring the voltage drop across a $92 \Omega$ shunt resistor.

Cylindrical Langmuir probes were used to measure the electron number density and temperature. The probes consisted of $0.127 \mathrm{~mm}$ or $0.051 \mathrm{~mm}$ diameter tungsten wire encased in an alumina tube housing. The probe was biased with respect to ground using a Kepco bipolar power supply, and the ground-to-cathode potential was monitored to facilitate data presentation. For the purposes of analysis, the ions and electrons were assumed to form Maxwellian distributions, and thin sheath analysis was used for all of the data. These assumptions were justified for all of the data between $X=20$ and $X=50 \mathrm{~mm}$ since the Debye length was much shorter than the probe radius. At $X=10 \mathrm{~mm}$, the Debye length was of the order of the probe radius. While the collected probe current at $X=10 \mathrm{~mm}$ was orbital motion limited, this is typically only considered when evaluating electron number density. At all locations examined in this work, the electron and ion Larmor radii were much larger than the probe radius, and the effects of the magnetic field on the probe response were neglected. ${ }^{12}$ Information on the electron Larmor radii is presented later in this paper. Consequently the electron temperature was calculated using Equation 2:

$$
\mathrm{T}_{\mathrm{e}}=\frac{\mathrm{e}}{\mathrm{k}}\left\{\frac{\mathrm{d}\left(\ln \left(\mathrm{I}_{\mathrm{e}}\right)\right)}{\mathrm{dV}}\right\}^{-1}
$$

where $I_{e}$ is the electron current to the probe, and the derivative is evaluated as the slope of $\ln \left(I_{e}\right)$ near the floating potential. The plasma potential was determined by the inflection-point method where the peak of the first derivative of the probe current with respect to voltage defines the plasma potential. The electron number density was evaluated using Equation 3,

$$
n_{e}=\frac{l_{e, s}}{e A_{p}} \sqrt{\frac{2 \pi n_{e}}{k T_{e}}}
$$

by setting the current at plasma potential equal to the electron saturation current, $I\left(V_{p}\right)=I_{e . s}$. The effect of the magnetic field will be to impede the flow of electrons to the probe, which results in a reduction in the collected current and consequently the electron number density. ${ }^{12}$

The emissive probes were constructed from $0.064 \mathrm{~mm}$ diameter tungsten wire with a $4 \mathrm{~mm}$ long single loop to measure the local plasma potential. It was connected electrically by two $0.23 \mathrm{~mm}$ diameter tungsten wires and two much larger copper wires, which were mounted within a two hole ceramic insulator. For electrical and mechanical shielding the assembly was encased in a $2.6 \mathrm{~mm}$ diameter, thin wall stainless steel jacket. The spatial resolution was limited axially by the filament length of $2.5 \mathrm{~mm}$ and laterally by the support structure width of $1.5 \mathrm{~mm}$.

The filament was heated to emission with a $60 \mathrm{~Hz}$ half wave rectified heating current. The probe bias voltage with respect to ground was swept at $500 \mathrm{~Hz}$ with measurements taken during the off phase of the heater when the filament had a unipotential surface and a correction for longitudinal potential drop across the probe was unnecessary. The inflection point method with the current-voltage trace of a hot electron emitting filament was used to deternine the plasma potential. ${ }^{13}$

\section{Results and Discussion}

\section{Magnetic Field}

The Hall probes were used to measure the magnetic field generated by the thruster both with and without a discharge. Based on calibrations, sweep-to-sweep variations in the field strength, and conversion of data taken in transverse sweeps to radial information, the diagnostic was estimated to be accurate to within $+/-5 \mathrm{G}$. This number reflects possible misalignment of the thrust vector with respect to the probe and vibrations experienced by the probe during its traverse in front of the thruster. The larger fraction of this error was contributed by the structure, because examination of the calibration in Figure 5 a indicates resolution by the Hall generator of 1 to $2 \mathrm{G}$. The thermal 
design of the probes adequately protects the Hall generator from the heat flux of the thruster for short periods, and the positioning system was operated at 10 to $20 \mathrm{~cm} / \mathrm{s}$ to minimize the energy deposition to the probe during a sweep. Consequently, improving the overall accuracy would involve a redesign of the support structure to mitigate vibration at the speeds necessary to protect the probe.

Due to the proprietary nature of the magnetic field data, the values reported in this paper have been normalized to the maximum vacuum axial or radial field strength $5 \mathrm{~mm}$ from the exit plane, $X=5 \mathrm{~mm}$. Measurements during thruster operation were limited to within $15 \mathrm{~mm}$ axially from the exit plane. Attempts to probe closer resulted in perturbations in the operation of the D55. The tip of the probe extended $5 \mathrm{~mm}$ beyond the Hall generator, and the presence of a cool insulating surface at this distance caused the thruster current to rise to as much as $8 \mathrm{~A}$ while the assembly was directly downstream of the anode $(\sim Y=+/-27.5 \mathrm{~mm})$. It is believed that, due to this particular perturbation of the thruster, this position, $X=5 \mathrm{~mm}$, represents the axial extent of the closed drift of electrons in the D55.

A comparison of the magnetic field at $X=15 \mathrm{~mm}$ generated by both the electromagnets alone and the operating thruster is depicted in Figure 6 . Overall, the field strength at $Y=+/-25 \mathrm{~mm}$ diminished by less than $7 \mathrm{G}$; this was established by comparing the differences from both $Y=+25 \mathrm{~mm}$ and $\mathrm{Y}=-25 \mathrm{~mm}$. At least 95 percent of the vacuum field strength generated by the electromagnets alone remained during thruster operation. This limited the Hall current to several tens of Amperes, assuming it was the primary contributor to the change in the magnetic field. The small change also indicates that vacuum field measurements are within 5 percent of the discharge values. For applications where this error is acceptable, the magnetic field during thruster operation can be approximated by the vacuum field measurement. The benefit of this result is that a Gaussmeter or a simplified Hall probe is sufficient to map the magnetic field, and these devices offer improved capability for resolution compared to water-cooled Hall probes with their extensive thermal protection.

As a result of the small difference between the vacuum and discharge magnetic fields, Figures 7 and 8 present contour maps of the axial $(X)$ and radial vacuum magnetic fields at $5 \mathrm{~mm}$ from the exit plane, $X=5 \mathrm{~mm}$, obtained with the Gaussmeter. These maps show the geometry of the thruster for reference, and the scale is only approximate. The inner electromagnet generates the largest fraction of the magnetic field. The axial contours show a high degree of symmetry about the $X$-axis, although the outer electromagnet at $150^{\circ}$ to the $Y$-axis appears to be slightly stronger than the one at $30^{\circ}$. Given that the axial magnetic field was measured directly and is free of the numerical errors associated with calculating the radial field, this small perturbation is beyond the limits of the error in the measurement. The radial contour map shows a similar asymmetry. The strongest radial fields were observed in the third quadrant of the Y-Z plane. This type of asymmetry suggests that the outer electromagnet at $30^{\circ}$ is slightly weaker than its two counterparts. A misalignment of the probe system with respect to the thruster would result in one side of the thruster appearing to be stronger than the other, however, the indicators were more localized, suggesting a truly asymmetric magnetic field. It should also be noted that in Figure 8 , the radial field map shows a numerical defect in the range of $Z=35 \mathrm{~mm}$. The contours change abruptly in this region, and the phenomenon was absent in the axial field contours.

The fields downstream of $X=5 \mathrm{~mm}$ are expected to share the structure of those contours with a diminished scale. The axial variation of the radial field is presented in Figure 9, and shows the expected decay. These data were taken during thruster operation. This information was used to calculate the Larmor radius to establish the validity in neglecting magnetic field effects on electrostatic probe results.

\section{Ion Current Density}

Figure 10 depicts the variation of the ion current with axial distance from the thruster. The ion beam begins as an annulus, and within $40 \mathrm{~mm}$ of the discharge chamber, it has nearly coalesced to a single axisymmetric jet. Compared to a similar study of the SPT $-100^{10}$, the plume of the D55 focuses in a much shorter distance. The integrated ion currents are presented in Table 2. These currents were computed by summing the product of the current density at a position $(X, Y, 0)$ and the differential area

$$
A_{n}=\pi\left[\left(\frac{Y_{n+1}+Y_{n}}{2}\right)^{2}-\left(\frac{Y_{n}-Y_{n-1}}{2}\right)^{2}\right]
$$

where $n$ denotes the nth measurement of the ion current density. Given the symmetry in the ion current density measurements, only the data at positive values of $Y$ were used. At all axial locations, the ion current was lower than the discharge current. This was expected because ions born near the anode and in the acceleration region carry a 
fraction of the discharge current, while electrons diffusing through the closed drift to the anode provide the remaining current in the thruster. It should also be noted that the probe was always parallel to the axis of the thruster. At high angles between the flow and the probe face, the projected ion collection area is less than the value used in the calculations. Consequently the ion current density is underestimated at large positive and negative values of $Y$. The evolution of the beam as it propagates from the near field to the far field is depicted in Figure 11 . These plots are normalized to the peak value at each axial distance. The beam divergence was small in the near field, and grew uniformly beyond $X=40 \mathrm{~mm}$. The far-field data are also presented in Gulczinski, et al., ${ }^{14}$ and the design of the Faraday probe used for the measurements at $X=250 \mathrm{~mm}$ and $X=500 \mathrm{~mm}$ is presented in Marrese, et al. ${ }^{15}$

\section{Plasma Potential}

Both Langmuir and emissive probes were used to measure the plasma potential. The radial profiles of the plasma potential with respect to the cathode are plotted in Figure 12. While the accuracy of the inflection point method with an emissive probe is on the order of the filament temperature $(-0.2 \mathrm{eV})$, the fluctuations in the plasma potential were on the order of $1 \mathrm{~V}$. Therefore the emissive probe plasma potential measurements are reported as accurate to within $+/-1 \mathrm{~V}$. The error in the Langmuir probe estimates was determined by examining the width of the peak in the derivative of the probe current. The uncertainty in the Langmuir probe inflection point yielded an error of $+1-1$ $V$ for the data between $X=20 \mathrm{~mm}$ and $X=50 \mathrm{~mm}$. The derivative of the current was considerably more noisy at $X=10$ mm than at other locations, and consequently the error on these measurements was estimated to be $+/-3 \mathrm{~V}$. The two methods agree to within $3 \mathrm{~V}$ over most of the range, with the emissive probe yielding consistently lower potentials than the Langmuir probe. The difference is within the error of the two measurements. Between $20 \mathrm{~mm}$ and $50 \mathrm{~mm}$, the profiles are essentially flat with a slight dip toward the center. As expected, the potential decreases with axial distance from the exit plane. At $10 \mathrm{~mm}$, the plasma potential increases in the region of the discharge chamber. The increase is evidence of the extent of the acceleration region. Attempts to probe closer than $10 \mathrm{~mm}$ were unsuccessful since the probe interfered with the thruster operation. Plasma potentials were measured through $Y=+40 \mathrm{~mm}$ at $X=50 \mathrm{~mm}$ and were found to be symmetric within the accuracy claimed.

\section{Electron Temperature and Number Density}

The radial variation of the electron temperature is presented in Figure 13. Error analysis was based on the thin sheath Bohm ion saturation current model and the variation in the curve fits to the natural logarithm of the electron current. It was assumed that in the very near-field the flow vector was along the axis of the thruster, and the probe alignment with the axis minimized the error due to misalignment. ${ }^{16}$ This resulted in a typical accuracy of approximately $+/-10$ percent. At $X=10 \mathrm{~mm}$, the electron temperature peaked at $14.3 \mathrm{eV}$ which is slightly higher than reported values for other Hall thrusters. ${ }^{10.17}$. The profile is similar in shape to the ion current density at the same location, and the peak was located within the mean radius of the discharge chamber. The peaked structure was still apparent at $X=20 \mathrm{~mm}$. However, the maximum was poorly defined in comparison to the one at $10 \mathrm{~mm}$, and the peak electron temperature dropped to $3.9 \mathrm{eV}$. The peak of the profile continues to move toward the thruster axis at $X=30 \mathrm{~mm}$ and $X=40 \mathrm{~mm}$. At $X=50 \mathrm{~mm}$, the peak appears to be around $Y=-20 \mathrm{~mm}$. As the electrons move axially, they continued to be cooled, and the magnitude of the radial variation diminishes in the very near-field. The ion beam focuses to single column within $40 \mathrm{~mm}$ of the exit plane, and the electrons follow the ions to maintain quasineutrality in the beam. However, the high energy electrons follow the beam more loosely than the cold electrons. This manifests itself in peak electron temperatures at some radial distance from the core of the beam, which is effectively the trend illustrated in Figure 13. While all of these data were taken in the range $Y=-40 \mathrm{~mm}$ to $Y=0 \mathrm{~mm}$, it is expected that the plasma is axisymmetric in the range of $X<30 \mathrm{~mm}$. Data taken at $X=50 \mathrm{~mm}$ and $Y>0 \mathrm{~mm}$ indicated lower temperatures on the cathode side of the thruster axis. This result is similar to the work by Myers and Manzella ${ }^{18}$ which showed that increasing the cathode flowrate depresses the electron temperatures.

Figure 14 shows the axial variation of the electron number density calculated based on the electron saturation current. These data have an accuracy of $+/-50$ percent. As expected, the profile at $X=10 \mathrm{~mm}$ had peak in the region of the discharge chamber. The peak moved to the thruster axis within $40 \mathrm{~mm}$ of the exit plane. This structure was similar to that observed with the ion current density. A first order calculation of the ion number density based on the local ion current density and a $300 \mathrm{~V}$ accelerating potential resulted in comparable number densities, satisfying the quasineutrality condition in the plasma. 


\section{Probe Considerations}

As stated previously, the thin sheath treatment of the Langmuir probe data is only valid if the following conditions are met:

where

$$
\begin{aligned}
& \frac{\lambda_{d}}{R_{p}} \ll 1 \\
& \frac{r_{L}}{R_{p}} \gg 1
\end{aligned}
$$

$$
\lambda_{\mathrm{D}}=\sqrt{\frac{\mathrm{kT}}{4 \pi n \mathrm{e}^{2}}} \quad \text { and } \quad \mathrm{r}_{\mathrm{L}, \mathrm{e}}=0.0238 \frac{\mathrm{T}_{\mathrm{e}}^{1 / 2}}{\mathrm{~B}}
$$

These lengths are in general smaller for electrons than ions, and therefore the electron Debye length and Larmor radius are examined here. Figure 15 depicts these lengths for the $X=10 \mathrm{~mm}$ and $X=20 \mathrm{~mm}$ cases. The probe used for the data at $X=20 \mathrm{~mm}$ and greater $X$ satisfied both of the conditions 5 and 6 , although at large radial distances, orbital motion may limit the current to the probe. At $X=10 \mathrm{~mm}$, the probe radius was of the order of the Debye length, and the sheath must be considered thick. The analysis by Bullock and Myers ${ }^{19}$ utilized the electron temperature computed as in this work with a curve fit for the numerical analysis of Laframbois ${ }^{20,21}$ to compute a solution for the electron number density. This analysis will be performed on the $X=10 \mathrm{~mm}$ data to refine the estimate of electron number density at this distance from the thruster.

In addition to the issues concerning the probe dimensions, the thin sheath analysis assumes Maxwellian distributions of both electron and ion energies. Research by Baranov, et al. ${ }^{22}$ has shown that the distribution at some locations have a high energy tail to the distribution. This result is supported by the shallow curvature observed in the plots of the natural logarithm of the electron current versus voltage; a Maxwellian population generates an entirely linear plot in the region of the floating potential. It is planned to examine the electron energy distribution function using the small modulating voltage method ${ }^{23.24}$ to determine the nature of the distribution and the magnitude of the temperature.

\section{Summary}

An extensive probe-based investigation of the very near-field plume and magnetic field of the D55 was conducted. Water-cooled Hall probes were used to measure the magnetic field generated by the electromagnets alone and during thruster operation. The results showed that the field present during thruster operation was between 95 and 100 percent of the strength of the vacuum field. Consequently only the vacuum field must be measured if this small inaccuracy can be tolerated. Additionally, the magnetic tield investigation showed some asymmetries possibly caused by uneven field generation by the electromagnets. Ion current densities were also measured, and the annular beam present at the discharge chamber coalesces into a single peaked profile within $40 \mathrm{~mm}$ of the exit plane of the thruster. Plasma potential was examined using both emissive and Langmuir probes, and at $X=10 \mathrm{~mm}$, the radial profile was sharply peaked near the discharge chamber. Electron temperature and number density were measured using cylindrical Langmuir probes. The electron temperature was depressed near the thruster axis, with a peak between 10 and $30 \mathrm{~mm}$ radially (i.e. within the annulus). Conversely the number density profiles were very similar to the ion current density curves, with a central peak $40 \mathrm{~mm}$ from the exit plane of the thruster.

Evaluation of the Debye lengths and Larmor radii showed that while the magnetic field is weak enough that thin sheath analysis is valid, the sheath was thick for the data taken at $X=10 \mathrm{~mm}$. This case of orbital motion limited current to the probe affects the number density estimates at this distance. Future work on this project seeks to reconcile the data with the theory by Latramboise. ${ }^{21}$ Additionally, the electron energy distribution function will be measured directly to refine the electron temperature measurements.

\section{Acknowledgments}

This research was supported by a research grant from NumerEx Corporation of Albuquerque, NM and the Jet Propulsion Laboratory, contract monitor Dr. Michael Frese. The D55 was provided by JPL. The authors thank Sasha Semenkin and Sergei Tverdokhlebov of TsNIIMASH for the generous and patient support in operating the D55. The authors also extend their gratitude to Dr. John E. Foster, Lyon B. King, Sven Bilen, Sang-Wook Kim, 
Frank S. Gulczinski III, and George Williams, for intellectual discussions, and Terry Larrow, Tom Griffin, and Gary Gould for their technical assistance. Additional thanks go to Sergei Khartov of the Moscow Aviation Institute for the use of the cathode.

\section{$\underline{\text { References }}$}

${ }^{1}$ Sankovic, J.M., Hamley, J.A., and Haag, T.W., "Performance Evaluation of the Russian SPT-100 Thruster at NASA LeRC," Proceedings of the 23rd International Electric Propulsion Conference, Sept. 1993, Seattle, WA, pp. 855-882.

2 Gamer, C.E., Brophy, J.R., Polk, J.E., Semenkin, S., Garkusha, V., Tverdokhlebov, S., and Marrese, C., "Experimental Evaluation of the Russian Anode Layer Thruster," 3rd Russian-German Conference on Electric Propulsion Engines and Their Technical Applications, July 19-23, 1994, Stuttgart, Germany.

${ }^{3}$ On, D, and Hastings, D., "Axisymmetric PIC-DSMC Simulations of SPT PIumes," IEPC Paper No. 95-160, 24th International Electric Propulsion Conference, Sept. 19-23, 1995, Moscow, Russia.

${ }^{4}$ Rhee, M.S. and Lewis, M.J., "Numerical Simulation of Stationary Plasma Thruster Exhaust Plume," AIAA Paper No. 95-2928, 31st AIAA/ASME/SAE/ASEE Joint Propulsion Conference, July 10-12, 1995, San Diego, CA.

${ }^{5}$ Ganner, C.E., Brophy, J.R., Polk, J.E., Semenkin, S., Garkusha, V., Tverdokhlebov, S., and Marrese, C., "Experimental Evaluation of the Russian Anode Layer Thruster," 3rd Russian-German Conference on Electric Propulsion Engines and Their Technical Applications, July 19-23, 1994, Stuttgart, Germany.

${ }^{6}$ Garkusha, V., Podgornov, V.A., Semenkin, A.V., and Chislov, G.O., "Erosion Measurements at the 260-Hour Test of the Thruster with External Anode Layer," TsNIIMASH.

7 Manzella, D.M. and Sankovic, J.M., "Hall Thruster Ion Beam Characterization," AIAA Paper No. 95-2927, 31 st AIAA/ASME/SAE/ASEE Joint Propulsion Conference, July 10-12, 1995, San Diego, CA.

${ }^{8}$ Marrese, C.M., Polk, J.E., King, L.B., Gallimore, A.D., Semenkin, S., Garkusha, V., Tverdokhlebov, S., "Analysis of Anode Layer Thruster Guard Ring Erosion," IEPC Paper No. 95-196, 24th International Electric Propulsion Conference, Sept. 19-23, 1995, Moscow, Russia.

${ }^{9}$ Semenkin, A., private communication, January 1997.

${ }^{10}$ Kim, S.W., Foster, J.E., and Gallimore, A.D., "Very-Near-Field Plume Study of a $1.35 \mathrm{~kW}$ SPT-100," AIAA Paper No. 96-2972, 32nd AIAA/ASME/SAE/ASEE Joint Propulsion Conference, July 1-3, 1996, Lake Buena Vista, FL.

"Brown, S.C., Basic Data of Plasma Physics, AIP Press, Massachusetts Institute of Technology, 1994.

${ }^{12}$ Hutchinson, I.H., Principles of Plasma Diagnostics, Cambridge University Press, New York, 1992.

${ }^{13}$ Smith, J.R., Hershkowitz, N., and Coakley, P., "Inflection-point method of interpreting emissive probe characteristics," Review of Scientific Instruments, Vol. 50, No. 2, Feb. 1979.

${ }^{14}$ Gulczinski, F.S., Gallimore, A.D., Carlson, D.O., and Gilchrist, B.E., "Impact of Anode Layer Thruster Plumes on Satellite Communications," AIAA Paper No. 97-3067, 33rd AIAA/ASME/SAE/ASEE Joint Propulsion Conference, July 7-9, 1997, Seattle, WA.

${ }^{15}$ Marrese, C.M., Haas, J.M., Domonkos, M.T., Gallimore, A.D., Tverdokhlebov, S., and Garner, C.E., "D-100 Performance and Plume Characterization on Krypton," AIAA Paper No. 96-2969, 32nd AlAA/ASME/SAE/ASEE Joint Propulsion Conference, July 1-3, 1996, Lake Buena Vista, FL.

${ }^{16}$ Sonin, A.A., "Free-Molecule Langmuir Probe and-Its Use in Flowfield Studies," AIAA Journal, Vol. 4, No. 9 , Sept. 1966, pp. 1588-1596. 
17 Bishaev, A.M. and Kim, V., "Local Plasma Properties in a Hall-Current Accelerator with an Extended Acceleration Zone," Soviet Physics-Technical Physics, Vol. 23, 1978, pp. 1055-1057.

${ }^{18}$ Myers, R.M. and Manzella, D.H., "Stationary Plasma Thruster Plume Characteristics," Proceedings of the 23rd International Electric Propulsion Conference, Sept. 1993, Seattle, WA, pp. 893-912.

${ }^{19}$ Bullock, S.R. and Myers, R.M., "An Investigation of Magnetic Field Effects on Plume Density and Temperature Profiles of an Applied-Field MPD Thruster," Proceedings of the 23rd International Electric Propulsion Conference, Sept. 1993, Seattle, WA, pp. 1292-1307.

${ }^{20}$ Clung, P.M., Talbot, L., and Touryan, K.J., "Electric Probes in Stationary and Flowing Plasmas: Part 1. Collisionless and Transitional Probes," AIAA Journal, Vol. 12, No. 2, Feb., 1974, pp. 133-154.

${ }^{21}$ Laframboise, J.G., "Theory of Spherical and Cylindrical Langmuir Probes in a Collisionless, Maxwellian Plasma at Rest," UTIAS Report No. 100, June 1966, Toronto, Ontario.

${ }^{22}$ Baranov, V.I, Nazarenko, Yu.S., Petrosov, V.A., Vasin, A.I., and Yashnov, Yu.M., "Electron Distribution Function in Accelerator with Closed Electron Drift," Proceedings of the 24th International Electric Propulsion Conference, Sept. 1995, Moscow, Russia, pp. 440-444.

${ }^{23}$ Rundle, H.W., Clark, D.R., and Deckers, J.M., "Electron Energy Distribution Functions in an $\mathrm{O}_{2}$ Glow Discharge," Canadian Journal of Physics, Vol. 51, 1973, pp. 144-148.

${ }^{24}$ Druyvesteyn, M.J., Z. Phys., Vol. 64, 1930, pp. 781.

\begin{tabular}{cccccc}
$\begin{array}{c}\text { Discharge } \\
\text { Voltage (V) }\end{array}$ & $\begin{array}{c}\text { Discharge } \\
\text { Current (A) }\end{array}$ & $\begin{array}{c}\text { Anode Mass } \\
\text { Flowrate } \\
(\mathrm{mg} / \mathrm{s})\end{array}$ & $\begin{array}{c}\text { Cathode Mass } \\
\text { Flowrate } \\
(\mathrm{mg} / \mathrm{s})\end{array}$ & $\begin{array}{c}\text { Cathode- } \\
\text { Ground } \\
\text { Voltage (V) }\end{array}$ & $\begin{array}{c}\text { Tank Pressure } \\
(\text { Pa) }\end{array}$ \\
\hline 300 & 4.5 & 4.76 & 0.78 & $13-15$ & $8.3 \times 10^{-3}$
\end{tabular}

Table 1 - D55 Operating Conditions.

\begin{tabular}{cc} 
Axial (X) Location & $\begin{array}{c}\text { Integrated Ion } \\
\text { Current (A) }\end{array}$ \\
\hline (mm) & 3.85 \\
20 & 3.54 \\
30 & 3.63 \\
40 & 3.59
\end{tabular}

Table 2 - The Calculation of Ion Current Based on the Ion Current Density Measurements. 


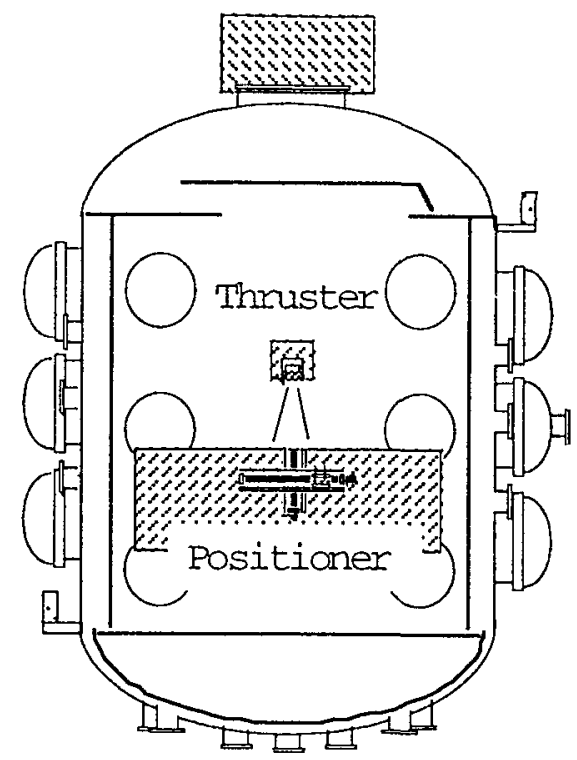

Fig. 1 - Schematic of the $6 \mathrm{~m}$ Diameter by $9 \mathrm{~m}$ Long Vacuum Chamber at PEPL

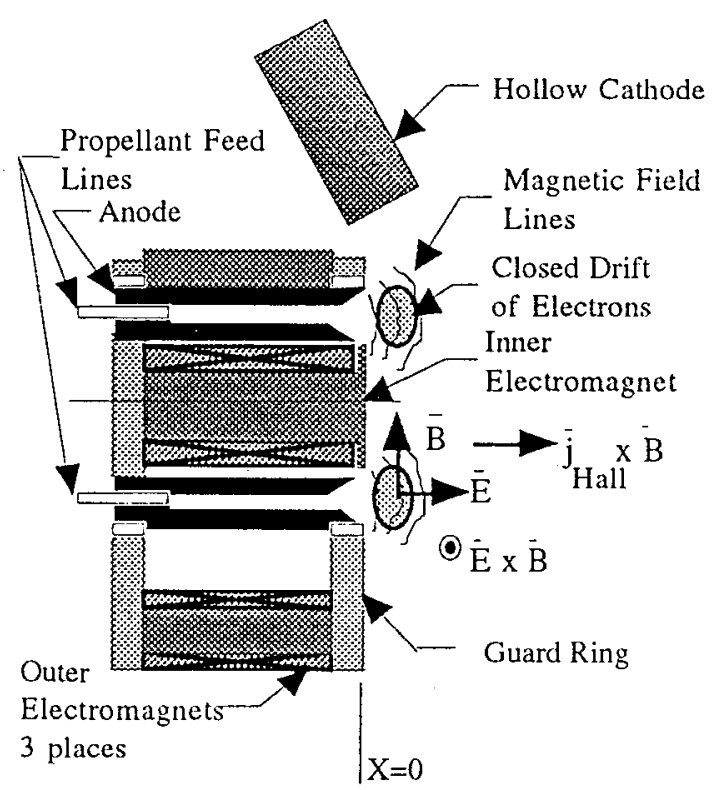

a) Side Section View

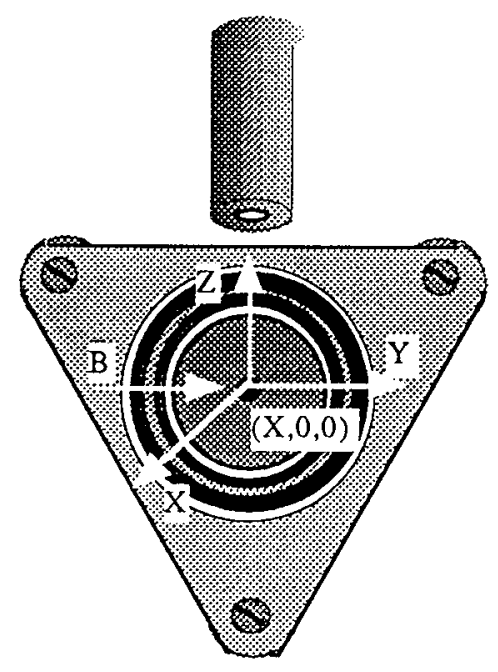

b) Front View

Fig. 2 - Schematic of the D55 Anode Layer Thruster

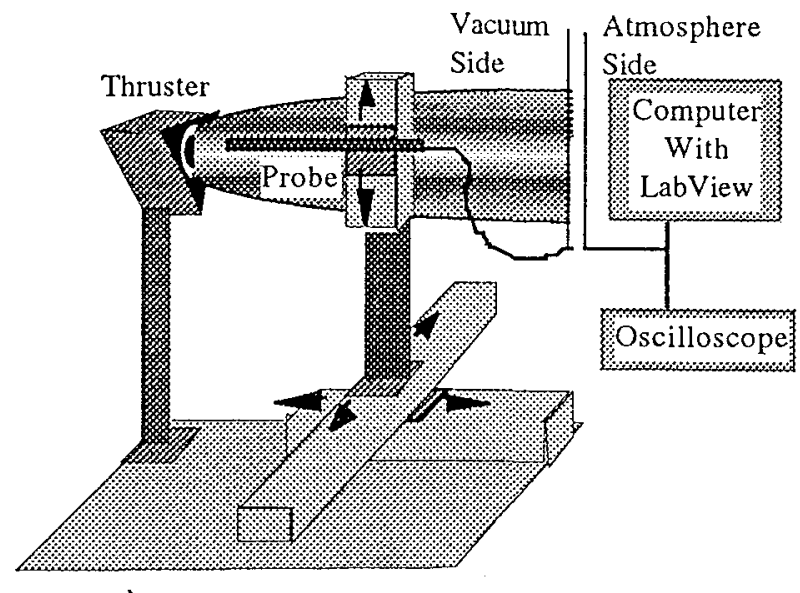

Fig. 3 - Illustration of the Three-Axis Probe Positioning System 


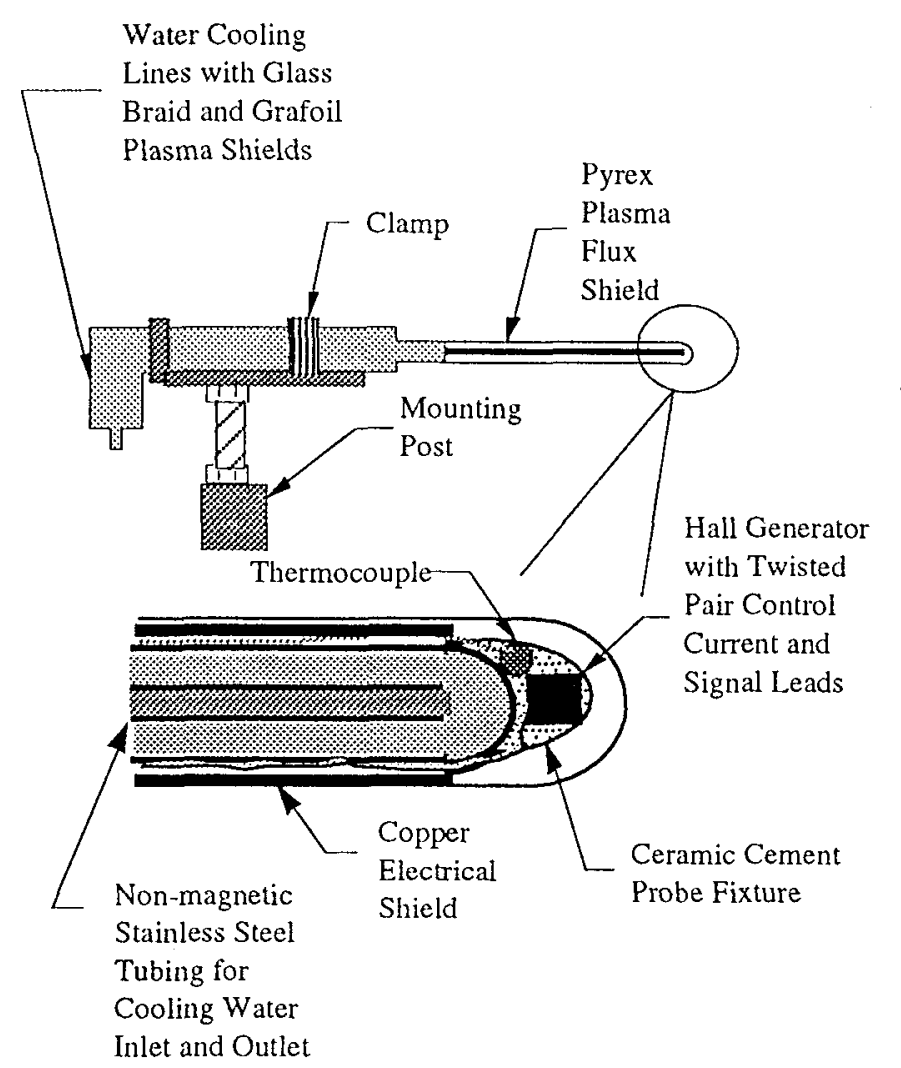

a) Mechanical Schematic

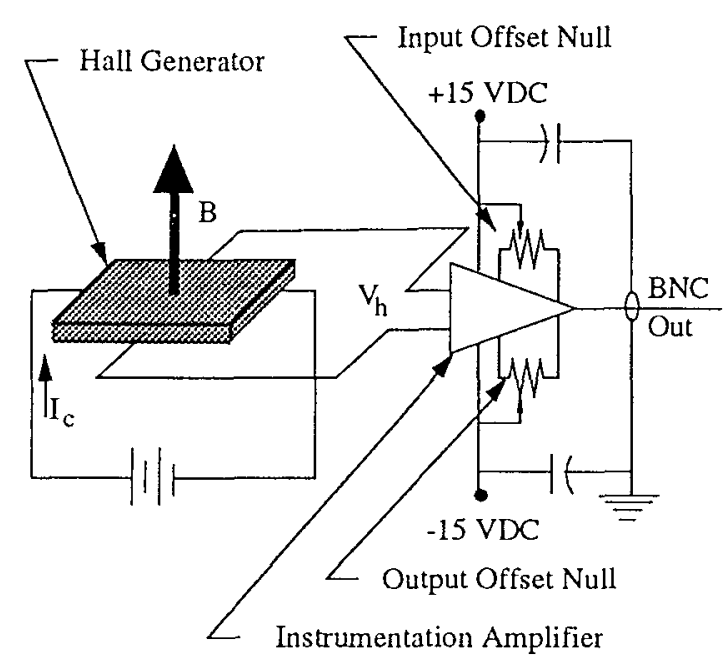

b) Electrical Diagram

Fig. 4 - Schematic of the Water-Cooled Hall Probes Used in the D55 Tests.

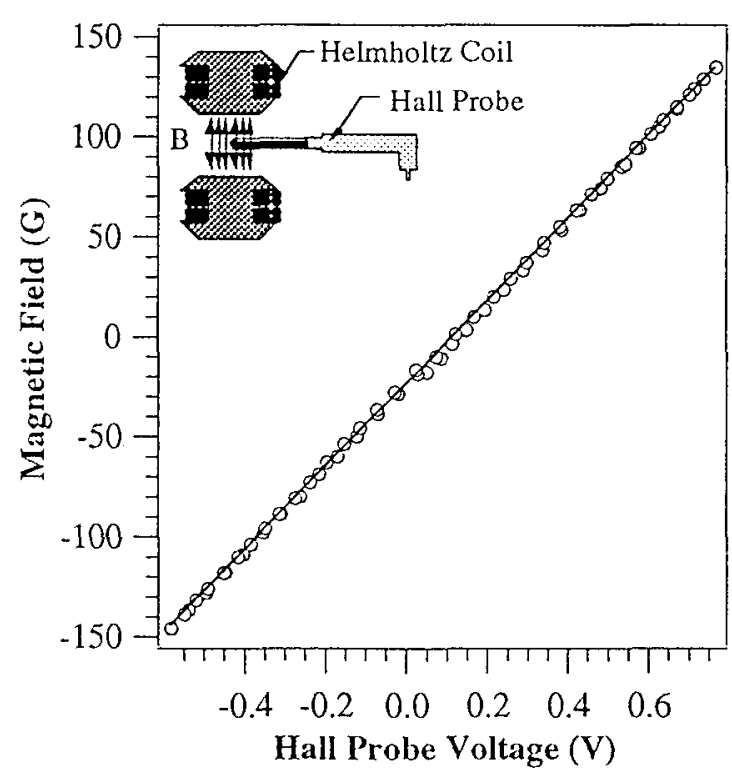

a) Hall Probe Calibration Curve.

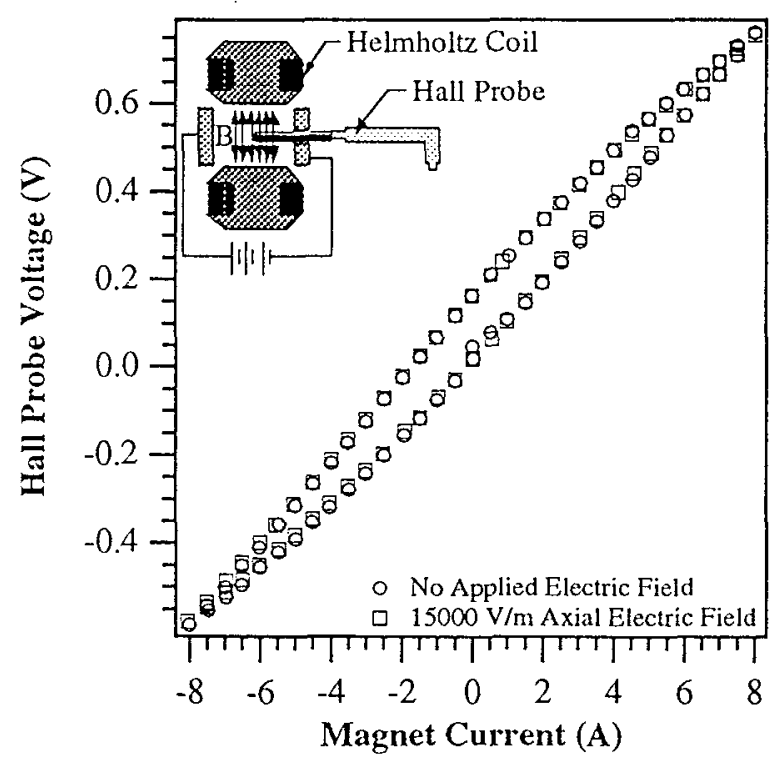

b) Evaluation of the Effect of a Strong Electric Field on Hall Probe Response.

Fig. 5 - Calibration of the Hall Probe. 


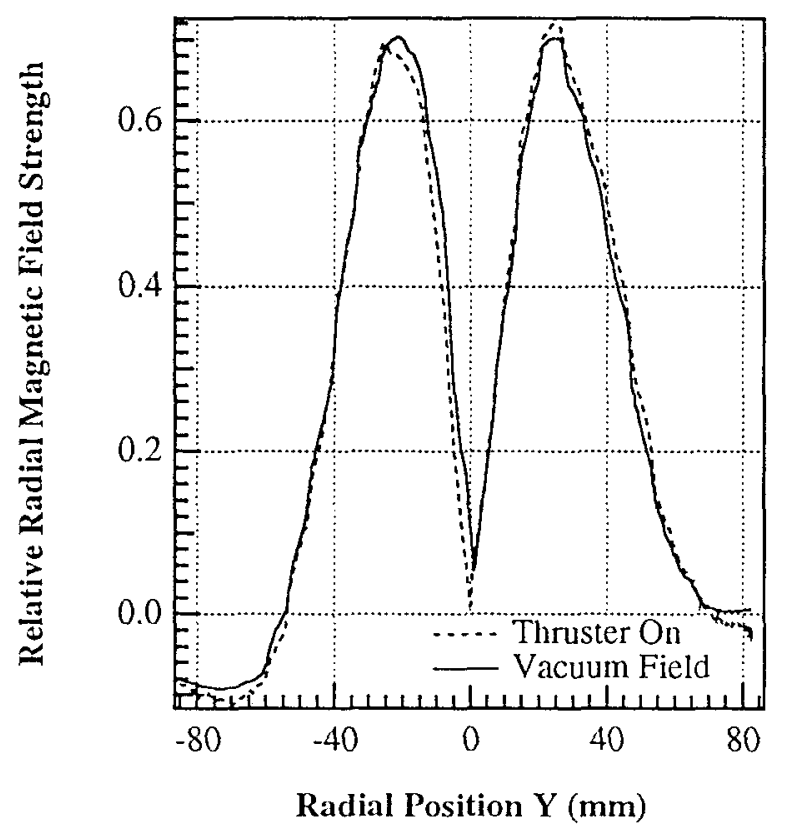

Fig. 6 - Comparison of the Vacuum Field Generated by the Electromagnets and the Field During Thruster Operation. $X=15 \mathrm{~mm}$. 


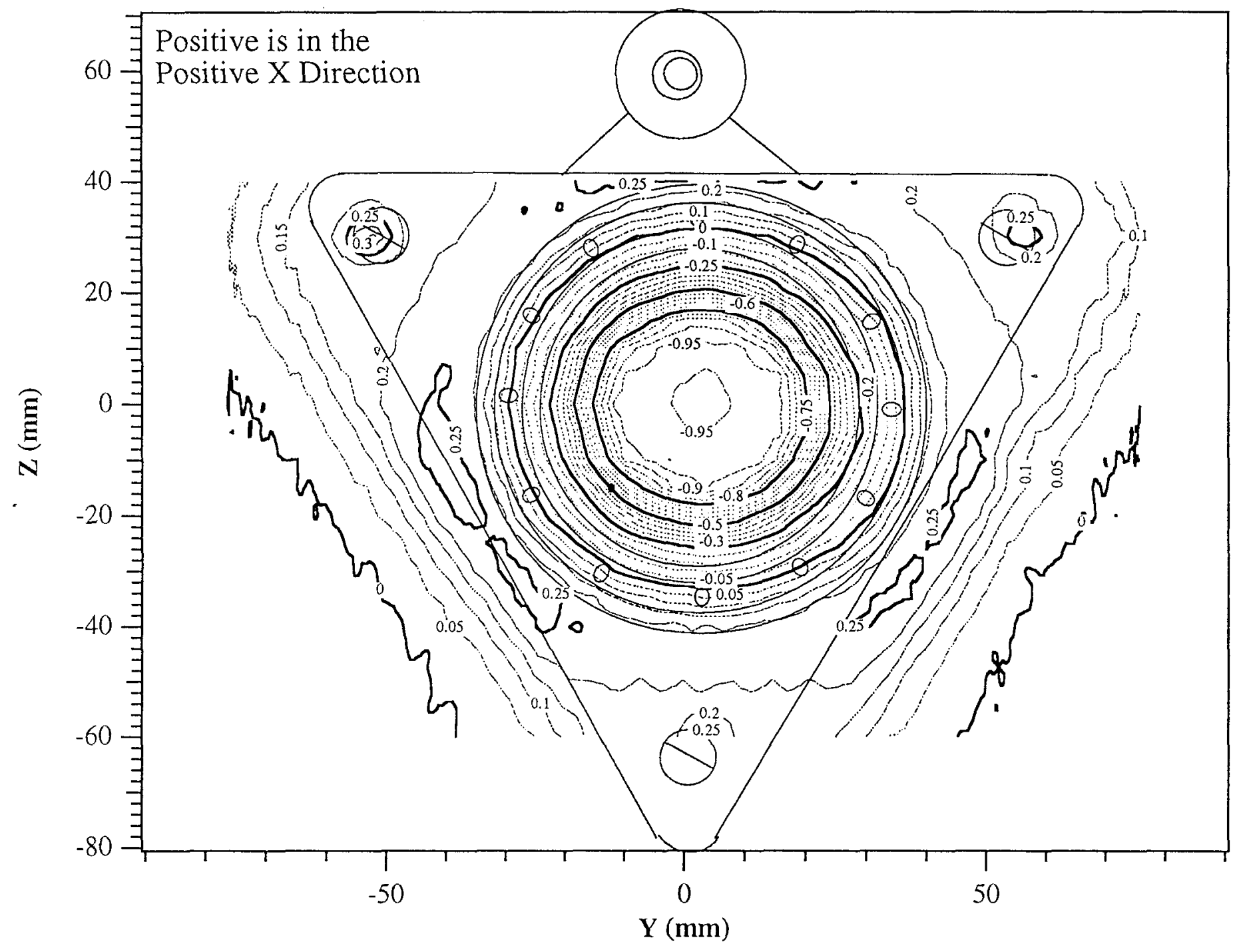

Fig. 7 - Axial Magnetic Field Contours $5 \mathrm{~mm}$ from the Exit Plane of the D55.

A Sketch of the D55 Face is Shown for Reference. Scale is Approximate. 


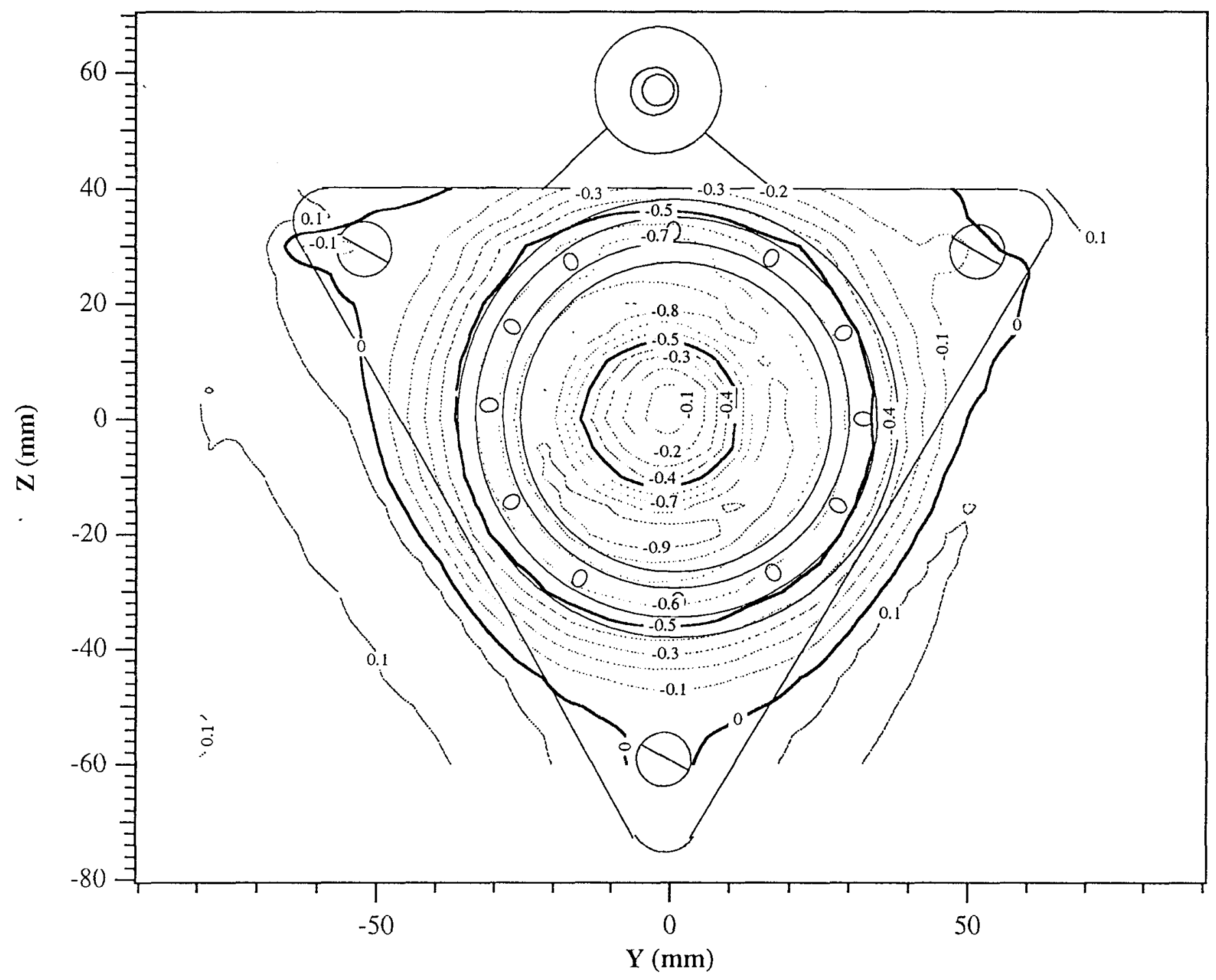

Fig. 8 - Radial Magnetic Field Contours $5 \mathrm{~mm}$ from the Exit Plane of the D55.

Positive Values Indicate a Radial Field Directed Away from the Axis.

A Sketch of the D55 Face is Shown for Reference. Scale is Approximate. 
Relative Radial Magnetic Field Strength
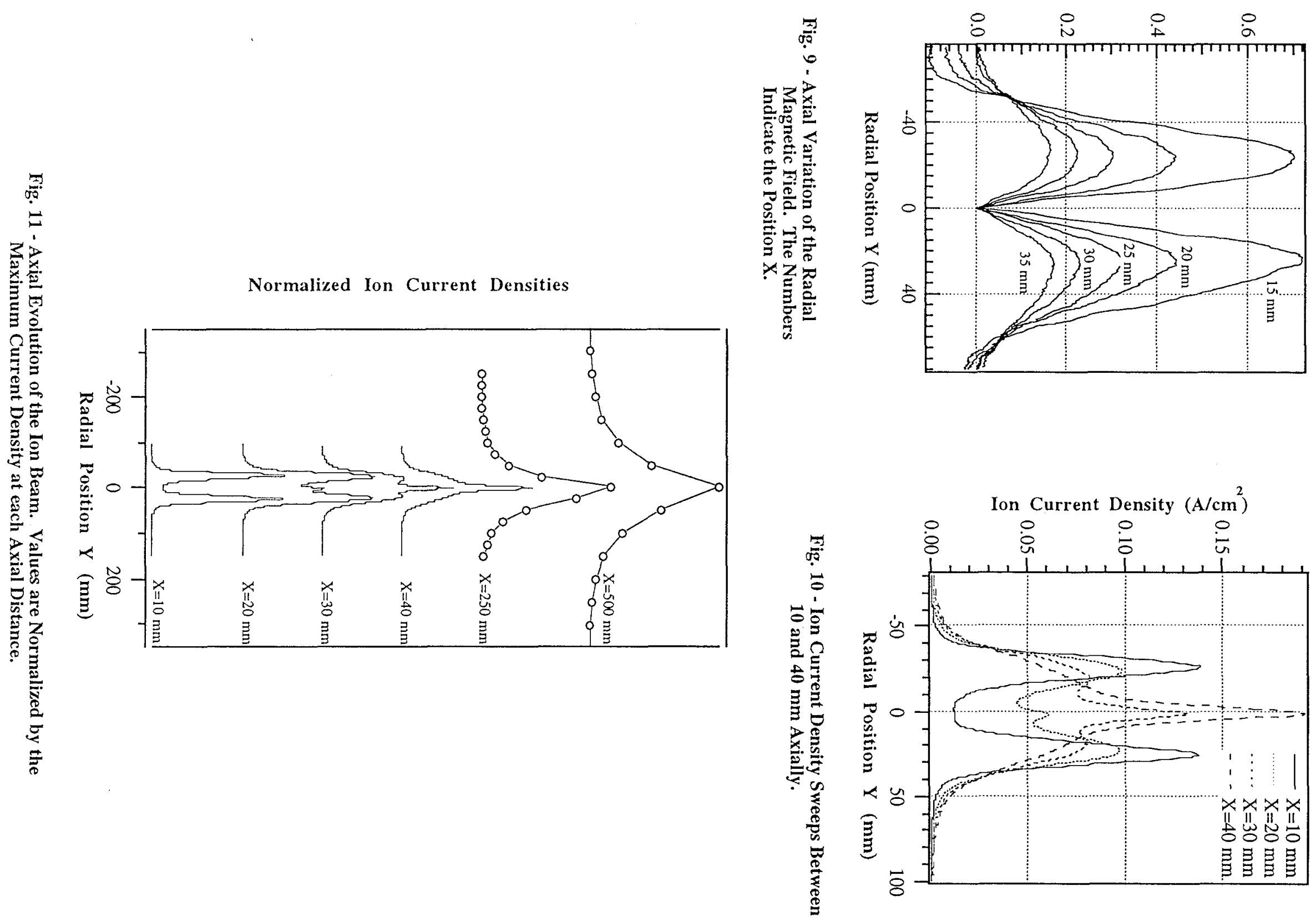

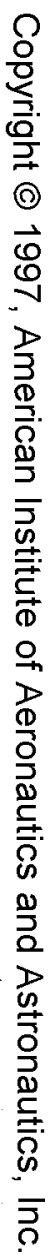




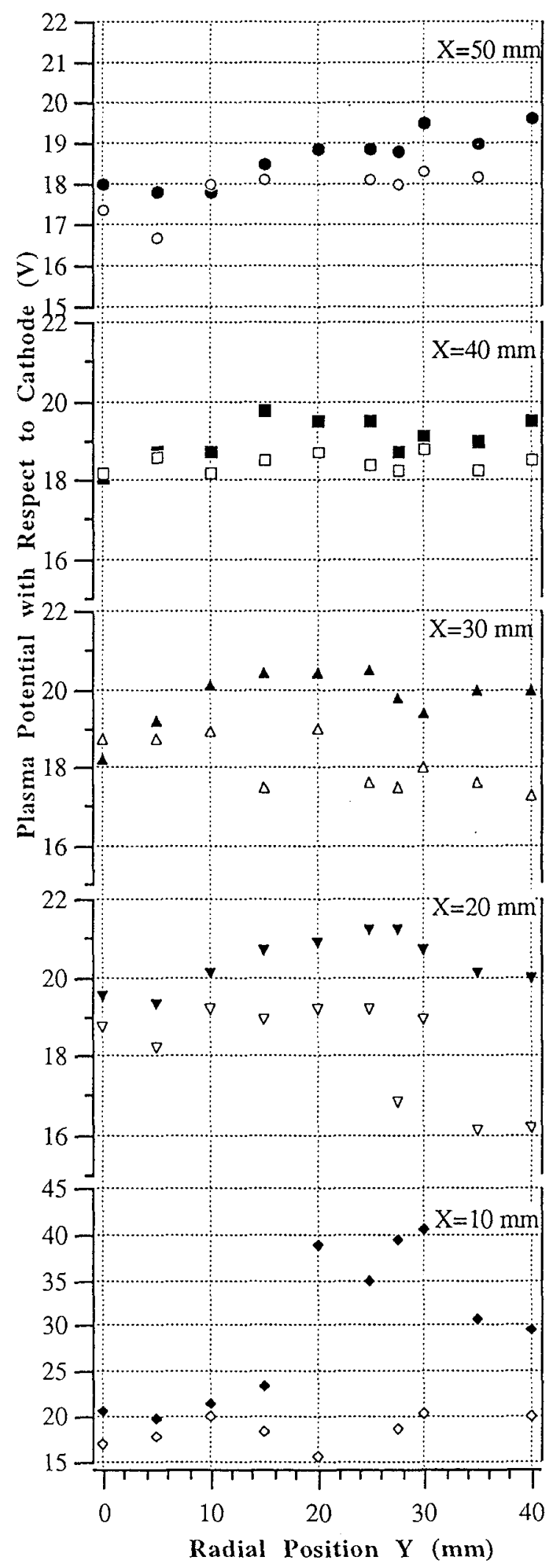

Fig. 12 - Plasma Potentials with Respect to Cathode in the Very Near-Field of the D55. Open Symbols Denote Data Taken with Emissive Probes. Closed Symbols Refer to Langmuir Probe Data.

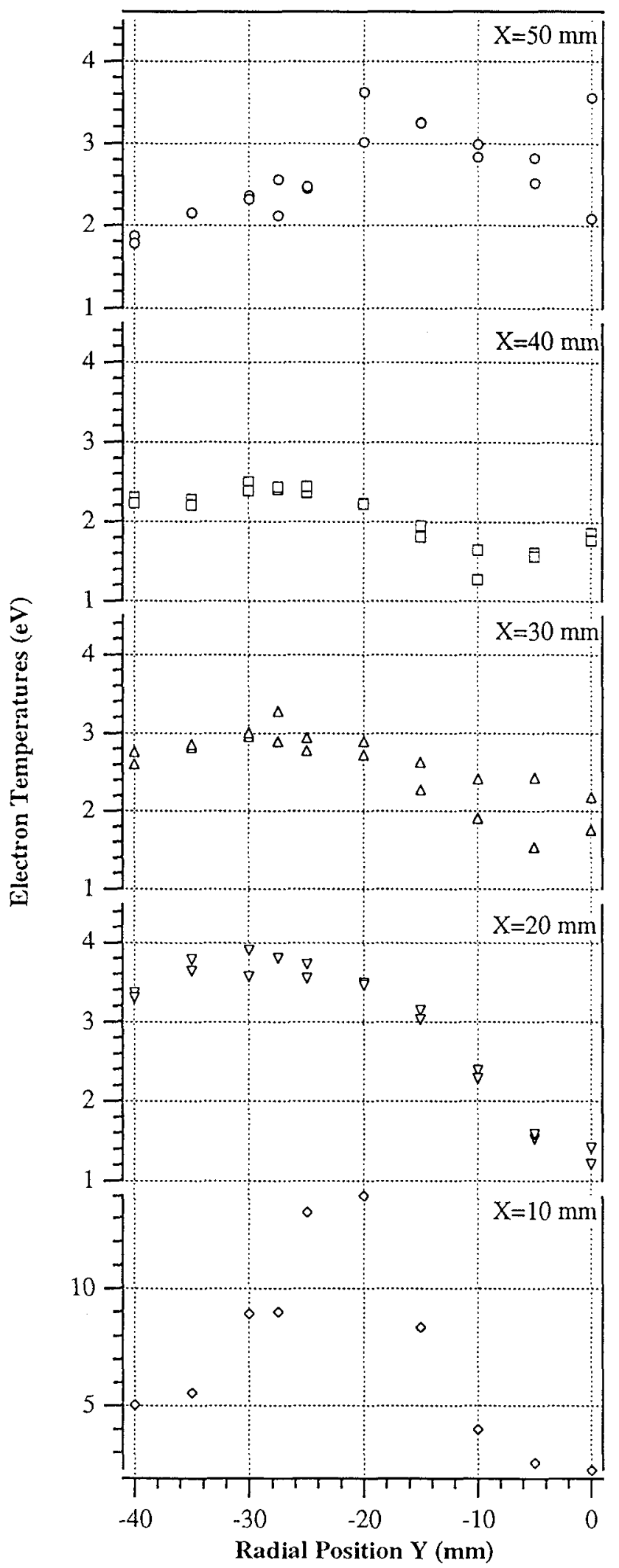

Fig. 13 - Electron Temperatures in the Very Near-Field of the D55. 

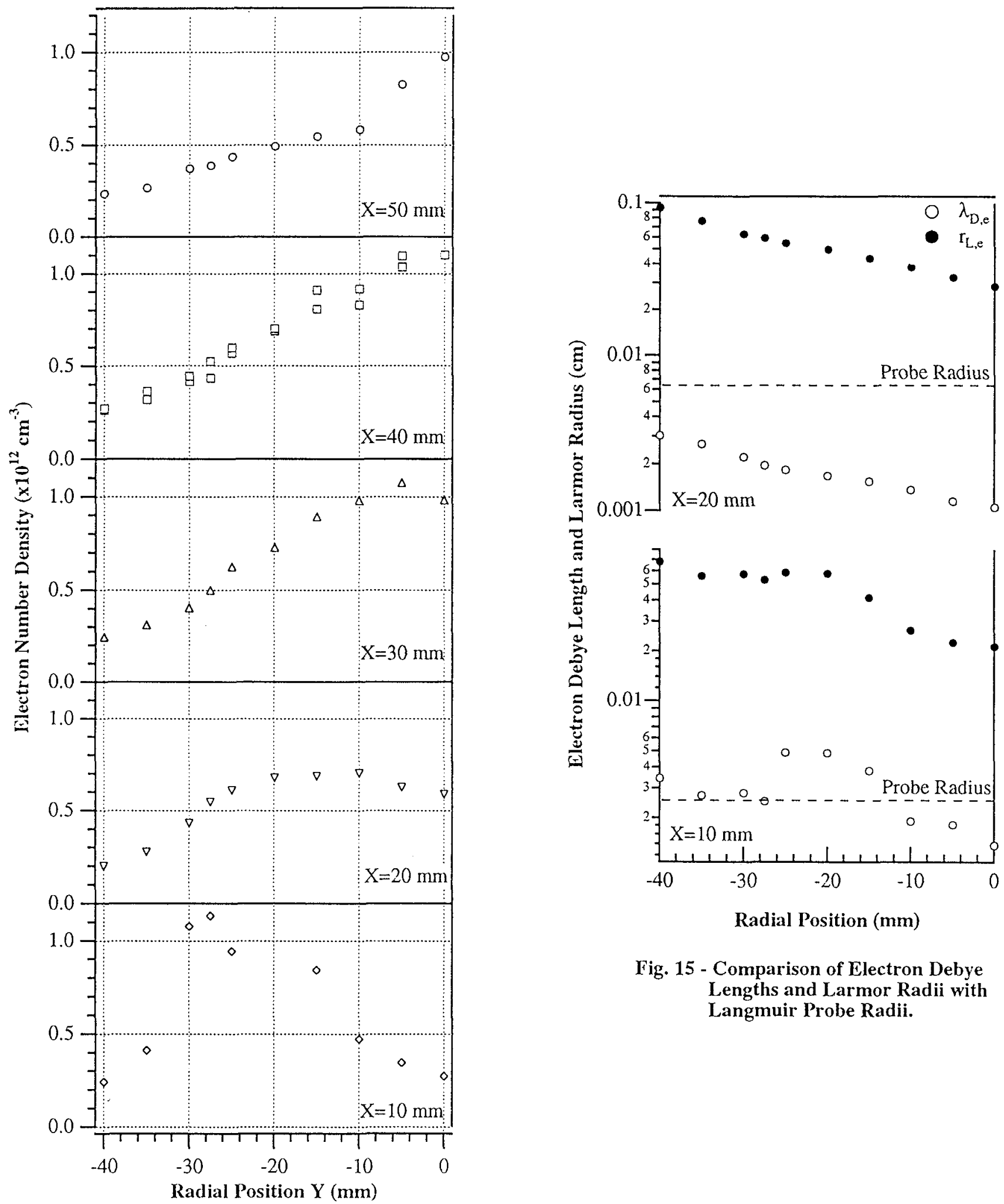

Fig. 15 - Comparison of Electron Debye Lengths and Larmor Radii with Langmuir Probe Radii.

Fig. 14 - Electron Number Densities in the Very Near-Field of the 055 . 